\title{
Hyaluronic acid concentration in the middle ear fluid as an indicator of severity of the secretory otitis in newborns with cleft palate
}

\author{
Karel Kotaška1⿴囗 , Lenka Hanousková1, Richard Průša1, Jiří Borský2, Petra Dytrych² and \\ Michal Jurovčík ${ }^{2}$
}

1Department of Medical Chemistry and Clinical Biochemistry, 2nd Medical Faculty, Charles University, University Hospital Motol, Prague, Czech Republic; 2 Department of ENT, 2nd Medical Faculty, Charles University, University Hospital Motol, Prague, Czech Republic

The aim of the study was to investigate the hyaluronic acid concentration in middle ear fluid of patients with cleft palate as an indicator of the severity of the disease. Hyaluronic acid was examined in the middle ear fluid of 65 children ( 48 boys and 17 girls) subjected to cleft lip surgery in neonatal period up to 10 days of age. Patients were divided into 3 groups according to the course of the disease. First group consists of 15 patients with favorable course, second group consist of 25 patients with moderate course, third group included 25 patients with an adverse course. Hyaluronic acid levels were determined by commercially available immunoassay. The concentrations of hyaluronic acid in the middle ear fluid were as follows (mean \pm SEM): favorable course: 14253 $\pm 2393 \mu \mathrm{g} / \mathrm{l}$, moderate course: $7503 \pm 1345 \mu \mathrm{g} / \mathrm{l}$, adverse course: $5905 \pm 2393 \mu \mathrm{g} / \mathrm{l}$. Patients with adverse course and moderate course had significantly decreased hyaluronic acid levels in middle ear fluid compared to the patients with favorable course $(P=0.02$ and $P=0.0018$ ). Hyaluronic acid concentration is related to the course of the disease and the lowest values are most frequent in patients with an adverse course.

Keywords: hyaluronic acid, middle ear fluid, newborns secretory otitis, cleft palate

Received: 21 April, 2021; revised: 25 June, 2021; accepted: 21 July, 2021; available on-line: 06 September, 2021

⿶e-mail: kotaska@email.cz

Acknowledgement of Financial Support: The research was supported by the project (Ministry of Health, Czech Republic) for conceptual development of research organization 00064203 (University Hospital Motol, Prague, Czech Republic).

Abbreviations: CLSI, Clinical laboratory standard institute; ELISA, enzyme linked immunosorbent assay; HA, Hyaluronic acid; HMW, high molecular weight; LMW, low molecular weight; MW, middle molecular weight; PBS, phosphate buffer saline

\section{INTRODUCTION}

Hyaluronic acid (HA) is a high molecular weight extracellular matrix polysaccharide involved in a number of important biological processes including regulatory, inflammatory, immunosuppressive, and anti-proliferative effects (Gudowska et al., 2017; Kotaška \& Trč, 2018; Marcuzzo et al., 2017). It is mainly involved in maintaining the viscoelasticity of liquid tissues, in the supramolecular spatial arrangement of proteoglycans in the extracellular matrix, and in the regulation of osmotic pressure, which significantly affects the homogeneity of the tissue and its homeostatic integrity. Due to its unique viscoelastic nature and non-immunogenicity, HA can also be used in a number of clinical applications, including joint fluid supplementation in osteoarthritis, to facilitate healing and regeneration of surgical wounds, as well as in ophthalmology, pharmacology, and cosmetics (Kotaška \& Trč, 2018). Current studies describe the use of hyaluronic acid as an important drug in otitis media effusion due to its anti-inflammatory and draining (mucociliar clearance) characteristics and for its ability to protect the mucous membranes (Abi Zeid Daou \& Bassim, 2020; Deng et al., 2018; Torretta et al., 2017; Torretta et al., 2016). Otitis media effusion is a non-inflammatory disease characterized by the presence of fluid of different viscosities in the middle ear and conductive hearing loss. Patients with cleft palate have severely impaired function of the Eustachian tube (Jurovcik et al., 2020). The result in almost all of them is the development of otitis media with effusion. (Torretta et al., 2017; Torretta et al., 2016). The aim of the study was to investigate the hyaluronic acid concentration in the middle ear fluid of patients with cleft palate as an indicator of the severity of the disease.

\section{PATIENTS AND METHODS}

Hyaluronic acid was examined in middle ear fluid of 65 children (48 boys and 17 girls aged from 2 to 10 days at the time of the middle ear fluid collection) subjected to cleft lip surgery in neonatal period. Informed consent was signed by the parents of the individuals enrolled to the study. University Hospital Ethical committee approved the background of the study. After collection, the samples were immediately transported to the laboratory and frozen at $-80^{\circ} \mathrm{C}$ until analysis. Just before analysis, samples were diluted 1:500 in Phosphate Buffer (PBS) buffer pH 7.0-7.2. Second dilution 1:20 was performed as a part of main analysis with buffer supplied in the reagent kit. Hyaluronic acid was determined by commercially available immunoassay kit TECO Hyaluronic acid PLUS ELISA (Sissach, Switzerland). The analytical characteristics of the method were as follows: working range $-2.7-1000 \mu \mathrm{g} / \mathrm{L}$, coefficient of variation $2.7-$ $5.2 \%$. Patients were divided into 3 groups according to the course of the disease. First group consisted of 15 patients with favorable course with none, or a maximum of 1 surgical procedure with the finding of a minimum of secretion without the need to insert middle ear drainage, in the further course with an airy middle ear. Second group consisted of 25 patients with moderate course, which included one surgical procedure with the finding of the secretion in the middle ear, a maximum of one 
insertion of middle ear drainage. Third group included 25 patients with the adverse course showing more than one surgery for indication of middle ear drainage. Patiens were under observation for at least two years after middle ear fluid collection.

\section{Statistical analysis}

The normality of the data distribution was tested with D'Agostino Pearson test. Differences between subgroups were tested for statistical significance by the nonparametric Mann-Whitney test. Value of $P<0.05$ was considered as statistically significant. Statistical software MedCalc version: 13.02.01 (Oostende, Belgium) and GraphPad Prism version 8.02 (San Diego, CA) were used for statistical evaluation.

\section{RESULTS}

The concentrations of hyaluronic acid in the middle ear fluid were as follows (mean \pm S.E.M.): favorable course: $14253 \pm 2393 \mu \mathrm{g} / \mathrm{L}$, moderate course: $7503 \pm 1345 \mu \mathrm{g} / \mathrm{L}$ adverse course: $5905+2393 \mu \mathrm{g} / \mathrm{l}$. The differences of HA values were significant. Patients with an adverse and moderate course had significantly decreased hyaluronic acid levels in the middle ear fluid compared to patients with a favorable course $(P=0.02$ and $P=0.0018)$. See Fig. 1 .

\section{DISCUSSION}

The presented results confirm the theory that the concentrations of hyaluronic acid in the middle ear fluid correlate with the severity of middle ear pathology including secretory otitis.

Increased concentrations of hyaluronic acid have been presented in patients with the favorable course of disease. Patients with a favorable course of secretory otitis ventilated the middle ear without the need for tubing ventilation. On the other side, patients with an adverse course had decreased hyaluronic acid concentrations and required repeated surgical intervention and middle ear drainage. Problems with middle ear ventilation usually accompany patients with cleft palate for the rest of their lives. In adverse cases, there is a tendency to prolonged difficulties and recurrences. If the middle ear secretion is not drained, it thickens. Gradually, the adhesive changes

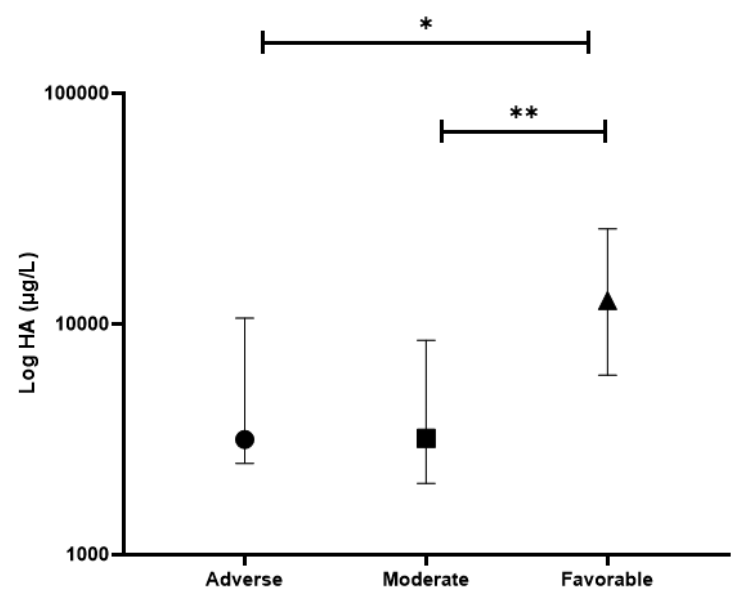

Figure 1. Hyaluronic acid concentrations in middle ear fluid of patients with secretory otitis after cleft lip surgery Results are expressed as median with interquartile range. of the eardrum develop and the middle ear bones are fixed. The condition can progress to chronic otitis with cholesteatoma (Abi Zeid Daou \& Bassim, 2020). Current studies also show that therapeutic intranasal administration of hyaluronic acid significantly improves the course of otitis media with effusion (Cioffi et al., 2017; Topazio $\mathrm{D}$ et al., 2019; Torretta et al., 2016). Reference values of HA in the middle ear fluid have not yet been published. We investigated HA concentration in control group of patients after palatoplasty with no sign of otitis and we evaluated reference interval according to the Clinical Laboratory Standard Institute (CLSI-EP 28A3c) approach using robust method with non parametric bootstrap procedure (Horowitz, 2008). We calculated 90\% CI of reference interval in the range of $604-28014 \mu \mathrm{g} / \mathrm{L}$. We also compared the results found in the control group with the results of patients with secretory otitis, nevertheless the differences were not significant. The results of the pilot study showed high variability and overlapping of HA concentrations in the studied groups (primarily between adverse and moderate course of disease with nonsignificant differences). The overlap of HA concentrations is described in other biological materials including synovial fluid (Kotaska et al., 2021). Adverse and moderate courses required additional surgical intervention. The surgical interventions lead due to changes in physiological properties of hyaluronic acid (various viscosity and lubrication properties) showing high variability in HA concentrations. This could be explained by the fact that the diagnostic ELISA kit, used to determine the concentration of hyaluronic acid in the middle ear fluid, does not provide accurate information on the size and molar mass of the analyzed HA form. The relationship between HA fragment size and clinical manifestations of various diseases is documented (Buhren et al., 2016). High and middle molecular weight forms (HMW-HA; $>4 \times 10^{5}$ Dalton, and MMW-HA; $\left.5 \times 10^{4}-4 \times 10^{5} \mathrm{Da}\right)$ are reported to have protective effects, while low molecular weight forms (LMW-HA; $<5 \times 10^{4}$ Dalton) show significant pro-inflammatory, angiogenic, and immunostimulatory activity (Buhren et al., 2016).

\section{CONCLUSION}

Hyaluronic acid concentrations in the middle ear fluid of patiens with cleft palate are related to the course of the disease and the lowest values are most frequent in patients with an adverse course. Hyaluronic acid in the ear fluid is a relevant marker of secretory otitis.

\section{Declaration of interest}

The authors declared no potential conflicts of interest with respect to the research, autorship, and/or publication of this article.

\section{Ethical approval}

University Hospital Ethical committee approved the background of the study. Informed consent was signed by the parents of the individuals enrolled to the study.

\section{REFERENCES}

Abi Zeid Daou C, Bassim M (2020) Hyaluronic acid in otology: Its uses, advantages and drawbacks - A review. Am J Otolaryngol 41: 102375. https://doi.org/10.1016/j.amjoto.2019.102375

Buhren BA, Schrumpf H, Hoff NP, Bolke E, Hilton S, Gerber PA (2016) Hyaluronidase: from clinical applications to molecu- 
lar and cellular mechanisms. Eur I Med Res 21: 1-7. https://doi. org/10.1186/s40001-016-0201-5

Cioffi L, Gallo P, D‘Avino A, Carlomagno F, Aloi G, D‘Onofrio A, Del Gaizo D, Giuliano M, De Franchis R, Sandomenico M. L, Pecoraro A (2017) Clinical improvement of subacute and chronic otitis media with effusion treated with hyaluronic acid plus hypertonic solution via nasal lavage: a randomized controlled trial. Glob Pediatr Health 4: 2333794X17725983. https://doi.org/10.1177/2333794X17725983

Deng R, Fang Y, Shen J, Ou X, Liuyan W, Wan B, Yuan Y, Cheng X, Shu Y, Chen B (2018) Effect of esterified hyaluronic acid as middle ear packing in tympanoplasty for adhesive otitis media. Acta Otolaryngol 138: 105-109. https://doi.org/10.1080/00016489.2017.1384057

Gudowska M, Cylwik B, Chrostek L (2017) The role of serum hyaluronic acid determination in the diagnosis of liver fibrosis. Acta Biochim Pol 64: 451-457. https://doi.org/10.18388/abp.2016_1443

Horowitz G (2008) CLSI EP 28A3c-Defining, Establishing, and Verifying Reference Intervals in the Clinical Laboratory, 3rd edn. Clinical Laboratory Standard Institute, Wayne, PA

Jurovcik M, Borsky J, Dytrych P, Černý M, Velemínská J, Jaklová L, Kotaška K, Hanousková L, Skřivan M (2020) First symptoms of secretory otitis media in newborns operated for cleft defect in a tenyear group Otorionolaryngologie a Foniatrie 69: 55-60 (in Czech)

Kotaška J, Trč T (2018) Hyaluronic acid - characteristics, its imporatnce and clinical applications. Ortopedie 5: 221-225 (in Czech)
Kotaska J, Hanouskova L, Prusa R, Trc T, Kotaska K (2021) Concentration of hyaluronic acid in synovial fluid as an indicator of severity and degree of impairment in patients suffering from gonarthrosis. Acta Chir Orthop Traumatol Cech 88: 83-86

Marcuzzo AV, Tofanelli M, Boscolo Nata F, Gatto A, Tirelli G (2017) Hyaluronate effect on bacterial biofilm in ENT district infections: a review. Apmis 125: 763-772. https://doi.org/10.1111/apm.12728

Topazio D, Passali FM, Cama A, Martino F, DiMauro R, Tirabasso A, Varakliotis T, DiGirolamo S (2019) Intranasal hyaluronic acid improves the audiological outcomes of children with otitis media with effusion. Indian I Otol 25: 1155-1161

Torretta S, Marchisio P, Rinaldi V, Carioli D, Nazzari E, Pignataro L (2017) Endoscopic and clinical benefits of hyaluronic acid in children with chronic adenoiditis and middle ear disease. Eur Arch Otorbinolaryngol 274: 1423-1429. https://doi.org/10.1007/s00405016-4327-4

Torretta S, Marchisio P, Rinaldi V, Gaffuri M, Pascariello C, Drago L, Baggi E, Pignataro L (2016) Topical administration of hyaluronic acid in children with recurrent or chronic middle ear inflammations. Int J Immunopathol Pharmacol 29: 438-442. https://doi. org /10.1177/0394632016656012 